\title{
Differences in Vascular Reactivity Between Men and Women
}

Bob J. Schank, MS, * Luke S. Acree, MS, * Jessica Longfors, MS, * and Andrew W. Gardner, PhD, ${ }^{\dagger}$ Norman and Oklahoma City, OK

\begin{abstract}
The purpose of this study was to compare the gender- and age-related differences in vascular reactivity in healthy men and women across a wide age range. Fifty-seven men and 61 women between 20 and 89 years of age, free of cardiovascular disease and risk factors, were categorized into younger (20-39 years), middle-aged ( $40-59$ years), and older (60-89 years) age groups. Subjects were characterized on body weight and height, body mass index (BMI), and calf blood flow under resting, postocclusive reactive hyperemic (PORH), and maximal hyperemic conditions in the lower extremity with use of venous occlusion mercury strain-gauge plethysmography. Similar baseline characteristics were observed among age groups, whereas men had greater body weight $(p<0.05)$, higher BMI values $(p<0.05)$, and a trend toward higher ankle-brachial index $(\mathrm{ABI})$ values $(\mathrm{p}=0.054)$ than women. While calf blood flow measurements were similar for men and women at rest and at maximal hyperemic conditions, women had a greater percentage change in calf blood flow from rest to PORH than men $(p=0.046)$. After adjusting for body weight, $\mathrm{BMI}$, and $\mathrm{ABI}$, the percentage change in calf blood flow from rest to PORH was no longer significantly higher in the women $(p>0.05)$. Furthermore, the percentage change in calf blood flow from rest to PORH was negatively related to body weight $(r=-0.30$, $p<0.01)$ and to BMI $(r=-0.26, p<0.01)$ in the men and women. No differences $(p>0.05)$ in the calf blood flow measures were observed among the age groups. In a healthy cohort free of cardiovascular disease, increased BMI accounted for poorer vascular reactivity in men compared to women regardless of age.
\end{abstract}

Angiology 57:702-708, 2006

From the *Department of Health and Exercise Science, University of Oklahoma, Norman; and ${ }^{\top}$ CMRI Metabolic Research Center, University of Oklahoma Health Science Center, Oklahoma City, OK

Andrew W. Gardner, PhD, was supported by grants from the National Institute on Aging (NIA) (R01-AG-16685), by a University of Oklahoma Research Council grant, and by the University of Oklahoma Health Sciences Center General Clinical Research Center grant (M01-RR-14467) sponsored by the National Center for Research Resources from the National Institutes of Health

Correspondence: Andrew W. Gardner, PhD, Hobbs-Recknagel Professor, University of Oklahoma Health Science Center, CMRI Metabolic Research Center, 1122 NE 13th St, ORI-W 1400, Oklahoma City, OK 73117

E-mail: andrew-gardner@ouhsc.edu

DOI: 10.1177/0003319706295474

(C)2006 Sage Publications

\section{Introduction}

Advancing age has a profound effect on the structure and function of blood vessels and is a recognized risk factor for cardiovascular disease. ${ }^{1}$ Many of the changes experienced by the vascular system with age affect the ability of the vessels to respond to changes in blood flow in response to stimuli or in the maintenance of homeostasis through endothelium-dependent vasodilation. It has been reported that reduced endothelial vasodilatory function occurs in atherogenesis before histologic and angiographic evidence of atherosclerosis. ${ }^{2,3}$ In addition, impaired endothelium-de- 
pendent vasodilation is a common characteristic of several atherosclerotic risk factors including diabetes, ${ }^{4}$ hypertension, ${ }^{5}$ dyslipidemia, ${ }^{6}$ and aging, ${ }^{7}$ as well as all cardiovascular risk factors. ${ }^{8}$ These conditions that occur with declining endothelial function increase the susceptibility for the development of vasospasm, thrombus formation, and myocardial infarction. ${ }^{1}$

Aging is also a risk factor for the development of cardiovascular disease due to structural and functional changes that occur in the vasculature. ${ }^{1}$ It has been suggested that endothelial dysfunction begins before any detectable structural changes in the arterial wall during middle age. ${ }^{9}$ The age-related decline in vascular function is different between men and women, ${ }^{9}$ as men lose vasodilatory capacity gradually over time, while women experience rapid declines around the age of menopause. ${ }^{5,7}$

Numerous investigations have examined the declines in vascular reactivity with age,,$^{1,7,10-15}$ but few have examined the effect of gender., Furthermore, adiposity may partially explain differences in vascular reactivity between men and women of various age groups, as obesity and body fat distribution impair endothelium-dependent vasodilation. ${ }^{16}$ However, little attention has focused on the interaction between age and gender on vascular reactivity, and whether this interaction is affected by adiposity. Therefore, the primary purpose of this study was to compare the gender-related differences in vascular reactivity in healthy men and women across a wide age range. In addition, the role of body mass index (BMI) on vascular reactivity was also assessed to provide insight on how fatness may affect vascular tone.

\section{Methods}

\section{Subjects}

A total of 57 men and 61 women between 20 and 89 years of age who were ambulatory with no functional limitations were categorized into younger (20-39 years), middle-aged (40-59 years), and older (60-89 years) age groups. All subjects were evaluated at the Department of Health and Exercise Sciences Vascular Laboratory at the University of Oklahoma, Norman campus. Subjects were recruited from local newspaper advertisements, flyers, and via a mass e-mail mes- sage to faculty and staff of the University of Oklahoma. Subjects were excluded for the following conditions: (1) cognitive dysfunction, measured by a score below 24 on the minimental state examination questionnaire; (2) cardiovascular disease risk factors and comorbid conditions that included diabetes, hypertension, hyperlipidemia, coronary artery disease, peripheral arterial disease, stroke, myocardial infarct, arterial revascularization, and current smoking; and (3) other mobility-limiting diseases or conditions. The procedures used in this study were approved by the Institutional Review Board at the University of Oklahoma. Written informed consent and a research privacy form were obtained from each subject before the investigation.

\section{Measurements}

Medical History. Demographic information, selfreported smoking habits, cardiovascular risk factors, and comorbid conditions were obtained by using a medical history questionnaire before collection of the vascular measurements. In addition, height was obtained by use of a stadiometer, weight was recorded from a physician scale, and BMI was calculated as: weight $(\mathrm{kg}) /$ height $\left(\mathrm{m}^{2}\right)$. Blood pressure and heart rate were measured with a Critikon automated Dinamap sphygmomanometer following 10 minutes of supine rest, and ankle/brachial index (ABI) was obtained by Doppler ultrasound. ${ }^{17,18}$

Calf Blood Flow. Calf blood flow was obtained under resting, reactive hyperemic, and maximal hyperemic conditions in the lower extremity by use of venous occlusion mercury strain-gauge plethysmography. ${ }^{19}$ Subjects rested supine for 10 minutes, after which 5 measures were taken and averaged. Reactive hyperemia was then performed by inflating a thigh blood pressure cuff to at least $200 \mathrm{~mm} \mathrm{Hg}$ to induce arterial occlusion for 3 minutes. Measurement of postocclusive reactive hyperemia (PORH) calf blood flow was obtained within the first minute following the 3-minute occlusion. Following the PORH calf blood flow measurement, a maximal hyperemic test was performed by inflating the thigh cuff to at least $200 \mathrm{~mm} \mathrm{Hg}$ while subjects stood and performed heel raises for as long as they could tolerate. Maximal hyperemic calf blood flow was obtained within the first minute following the combined arterial occlusion and ischemic exercise. With use of these procedures, the test-retest intraclass reliability coefficient is $\mathrm{R}=0.86$ for calf blood flow. ${ }^{19}$ 
Statistical Analyses

Before statistical tests, data were analyzed for normality and to determine whether outlying data points existed. To determine the effects of age, gender, and the age by gender interaction on the clinical characteristics and the vascular measurements, a 2-factor (ie, age by gender) analysis of variance (ANOVA) was performed using the SPSS statistical package (version 11.5). A 2-factor analysis of covariance (ANCOVA) was performed to assess group differences in the vascular measurements after controlling for differences in clinical characteristics. Post-hoc independent t tests with Bonferroni adjustment to control for type 1 error rate were performed following the ANOVA and ANCOVA procedures to further evaluate mean differences between groups. Pearson correlation coefficients were also calculated to assess the relationships among weight, BMI, and hemodynamic measurements. Level of significance was set at $\mathrm{p}<0.05$. Measurements are presented as means \pm standard deviations.

\section{Results}

Baseline characteristics (Table I) were similar across age and gender groups, with the exception that men had greater body weight $(\mathrm{p}<0.001)$ and BMI $(p=0.043)$ than women. Pairwise comparisons found that men had greater body weight than women $(\mathrm{p}<0.017)$ for the middle-aged and older age groups.

Calf blood flow measured at rest was similar ( $p>0.05$ ) between men and women, and among the 3 age groups (Table II). A trend was observed $(p=0.072)$ for women to have higher measured values of PORH calf blood flow compared to men of similar age. Women had a greater percentage change in calf blood flow from rest to PORH than men $(p=0.046)$. Maximal calf blood flow and the percentage change in calf blood flow from rest to maximal hyperemic conditions were similar ( $p>0.05$ ) between men and women and among the 3 age groups.

The vascular measurements adjusted for body weight, BMI, and $\mathrm{ABI}$ are shown in Table III. The percentage change in calf blood flow from rest to PORH was no longer significantly higher in the women ( $p>0.05)$, and the trend for a higher absolute value of PORH calf blood flow in the women disappeared as well $(p>0.05)$. The ad- justed PORH calf blood flow showed a tendency to decline with advancing age $(\mathrm{p}=0.075)$. The adjusted maximal calf blood flow measurements remained similar $(\mathrm{p}>0.05)$ between men and women and among the 3 age groups.

Table IV displays the correlation coefficients between clinical and hemodynamic variables. BMI and body weight were both negatively correlated with calf blood flow measured at rest, the percentage change in calf blood flow from rest to $\mathrm{PORH}$, maximal calf blood flow, and the percentage change in calf blood flow from rest to maximal hyperemia. Neither BMI nor body weight was significantly correlated with PORH calf blood flow ( $p>0.05$ ), and age was not correlated with any of the calf blood flow measurements ( $\mathrm{p}>0.05)$.

\section{Discussion}

The major findings of this investigation were the following: (1) younger, middle-aged, and older women had a greater percentage change in calf blood flow from rest to PORH than men; (2) after adjustment for body weight, BMI, and ABI, the gender differences in the percentage change in calf blood flow from rest to PORH were no longer evident; and (3) BMI was negatively and significantly related to the percentage changes in calf blood flow from rest to PORH and maximal hyperemia, and to the absolute calf blood flow value obtained during maximal hyperemia

Our findings that men have impaired vascular reactivity compared to women do not agree with previous reports. ${ }^{7,9}$ In these studies, men and women had similar vascular measurements at young and middle age, ${ }^{9}$ suggesting that vascular reactivity is preserved through middle age in both men and women and that vascular reactivity does not decline with age in premenopausal women. ${ }^{7}$ Both of these studies had large sample sizes and used techniques similar to the present investigation to measure vascular reactivity. Although BMI was shown to negatively correlate with the amount of vasodilation in men, ${ }^{7}$ vascular reactivity measures were not adjusted for BMI and are difficult to compare with this study. By controlling for BMI, we found that the gender differences in vascular reactivity are no longer evident, suggesting that adiposity levels contribute to the variations in vascular reactivity seen between men and women at each age group. 
Table I. Clinical characteristics of younger, middle-aged, and older men and women. Values are means \pm standard deviations.

\begin{tabular}{|c|c|c|c|}
\hline Variable & Men & Women & $\begin{array}{l}\text { Significance From } \\
\text { ANOVA }\end{array}$ \\
\hline \multicolumn{4}{|l|}{ Age, yr } \\
\hline Younger group & $29 \pm 5$ & $30 \pm 6$ & Age; $\mathrm{p}<0.001$ \\
\hline Middle-aged group & $49 \pm 6$ & $50 \pm 6$ & Gender; $\mathrm{p}=0.894$ \\
\hline Older group & $71 \pm 7$ & $70 \pm 7$ & Age $\times$ gender; $p=0.709$ \\
\hline \multicolumn{4}{|l|}{ Weight, kg } \\
\hline Younger group & $82.5 \pm 13.0$ & $72.3 \pm 23.8$ & Age; $p=0.854$ \\
\hline Middle-aged group & $91.5 \pm 16.6$ & $67.0 \pm 11.3^{*}$ & Gender; $\mathrm{p}<0.001$ \\
\hline Older group & $84.3 \pm 14.6$ & $71.2 \pm 14.7^{*}$ & Age $\times$ gender; $p=0.102$ \\
\hline \multicolumn{4}{|l|}{ BMI } \\
\hline Younger group & $26.8 \pm 4.2$ & $25.9 \pm 6.2$ & Age; $p=0.451$ \\
\hline Middle-aged group & $29.4 \pm 5.2$ & $26.1 \pm 4.0$ & Gender; $p=0.043$ \\
\hline Older group & $27.7 \pm 3.5$ & $26.2 \pm 5.7$ & Age $\times$ gender; $p=0.534$ \\
\hline \multicolumn{4}{|l|}{ Rest ABI } \\
\hline Younger group & $1.14 \pm 0.14$ & $1.09 \pm 0.10$ & Age; $p=0.295$ \\
\hline Middle-aged group & $1.16 \pm 0.10$ & $1.14 \pm 0.11$ & Gender; $\mathrm{p}=0.054$ \\
\hline Older group & $1.18 \pm 0.10$ & $1.13 \pm 0.08$ & Age $\times$ gender; $p=0.678$ \\
\hline
\end{tabular}

Sample sizes of the groups are as follows: younger men $(n=19)$, younger women $(n=15)$, middle-aged men $(n=21)$, middle-aged women $(n=23)$, older men $(n=17)$, older women $(n=23)$. *Significantly different from men $(\mathrm{p}<0.017)$. ABI $=$ ankle brachial index; ANOVA $=$ analysis of variance; BMI = body mass index.

BMI appears to be an important factor explaining differences in vascular reactivity in healthy men and women across a wide age range. This notion is supported by our findings that (1) men had higher BMI values and reduced vascular reactivity than women, (2) BMI was indirectly related to vascular reactivity, and (3) no difference in vascular reactivity existed between men and women after adjusting for BMI, body weight, and ABI. These findings suggest that the poorer vascular reactivity observed in men may be due to their greater adipose tissue. Our finding agrees with a previous report showing that overweight and obese individuals have altered vascular reactivity, although the mechanisms are not clear. ${ }^{20}$ Other studies have found that BMI is inversely related to blood flow measurements ${ }^{20-23}$ and endothelium-dependent vasodilation, ${ }^{9}$ whereas other studies have found that BMI is related to arterial stiffness, ${ }^{20}$ elevated blood viscosity, ${ }^{21}$ and increased platelet aggregation and arterial thrombosis. ${ }^{22}$ One possible mechanism for the adiposemediated endothelial dysfunction is that increased concentrations of leptin result in declines in endothelial nitric oxide production. ${ }^{23}$

Age did not influence vascular reactivity in men and women in the present study, as no differences were found among the 3 age groups. Our finding supports a previous report in which age did not affect vascular reactivity in men, ${ }^{9}$ suggesting that factors associated with age, such as BMI, have greater impact on vascular reactivity than age per se. Furthermore, the lack of an age effect on vascular reactivity in women lends ad- 
Table II. Blood flow measurements in younger, middle-aged, and older men and women. Values are means \pm standard deviations.

\begin{tabular}{|c|c|c|c|}
\hline Variable & Men & Women & $\begin{array}{l}\text { Significance From } \\
\text { ANOVA }\end{array}$ \\
\hline \multicolumn{4}{|c|}{ Rest blood flow $\left(\mathrm{mL} / 100 \mathrm{~mL} \cdot \mathrm{min}^{-1}\right)$} \\
\hline Younger group & $3.83 \pm 1.81$ & $3.40 \pm 1.74$ & Age; $p=0.646$ \\
\hline Middle-aged group & $2.98 \pm 1.39$ & $3.18 \pm 1.16$ & Gender; $\mathrm{p}=0.632$ \\
\hline Older group & $2.96 \pm 1.37$ & $3.88 \pm 4.83$ & Age $\times$ gender; $\mathrm{p}=0.534$ \\
\hline \multicolumn{4}{|c|}{ PORH blood flow $\left(\mathrm{mL} / 100 \mathrm{~mL} \cdot \mathrm{min}^{-1}\right)$} \\
\hline Younger group & $9.80 \pm 5.38$ & $10.55 \pm 6.32$ & Age; $p=0.128$ \\
\hline Middle-aged group & $6.55 \pm 5.42$ & $10.18 \pm 7.04$ & Gender; $\mathrm{p}=0.072$ \\
\hline Older group & $6.68 \pm 4.60$ & $8.16 \pm 4.83$ & Age $\times$ gender; $\mathrm{p}=0.514$ \\
\hline \multicolumn{4}{|l|}{ PORH $\% \Delta$ from rest } \\
\hline Younger group & $162 \pm 129$ & $225 \pm 162$ & Age; $p=0.259$ \\
\hline Middle-aged group & $123 \pm 159$ & $230 \pm 199$ & Gender; $\mathrm{p}=0.046$ \\
\hline Older group & $130 \pm 153$ & $139 \pm 119$ & Age $\times$ gender $; p=0.362$ \\
\hline \multicolumn{4}{|c|}{ Maximal blood flow $\left(\mathrm{mL} / 100 \mathrm{~mL} \cdot \mathrm{min}^{-1}\right)$} \\
\hline Younger group & $26.63 \pm 12.25$ & $25.96 \pm 10.34$ & Age; $p=0.162$ \\
\hline Middle-aged group & $18.44 \pm 9.44$ & $24.98 \pm 11.40$ & Gender; $\mathrm{p}=0.515$ \\
\hline Older group & $23.41 \pm 12.77$ & $21.53 \pm 7.44$ & Age $\times$ gender; p 0.167 \\
\hline \multicolumn{4}{|l|}{ Maximal $\% \Delta$ from rest } \\
\hline Younger group & $669 \pm 609$ & $843 \pm 640$ & Age; $p=0.709$ \\
\hline Middle-aged group & $560 \pm 326$ & $792 \pm 612$ & Gender; $\mathrm{p}=0.292$ \\
\hline Older group & $705 \pm 546$ & $613 \pm 355$ & Age $\times$ gender $; p=0.347$ \\
\hline
\end{tabular}

Sample sizes of the groups are as follows: younger men $(n=19)$, younger women $(n=15)$, middle-aged men $(n=21)$, middle-aged women $(n=23)$, older men $(n=17)$, older women $(n=23)$. ANOVA $=$ analysis of variance; $\mathrm{PORH}=$ postocclusive reactive hyperemia.

ditional support that women who have similar BMI values also have similar vascular reactivity regardless of their age.

Although the results of this study suggest that differences in vascular reactivity between men and women were related to differences in BMI and that age had minimal impact, several limitations exist. The cross-sectional design of this study does not imply a cause-and-effect relationship between vascular reactivity and BMI. Additional research is needed to further examine the relationship between vascular reactivity and adiposity by using more precise measurements of body fat than of BMI. Furthermore, a longitudinal research design examining change in vascular reactivity in men and women as they age would provide a more definitive assessment of the influence of age on vascular reactivity in men and women. Strengths of this study include recruiting men and women with a wide age range, as well as having sufficient sample size in the various groups. Based on the findings of this study, peripheral vascular reactivity is affected by BMI, suggesting that weight management 
Table III. Adjusted blood flow measurements in younger, middle-aged, and other men and women. Values are means \pm standard deviations.

\begin{tabular}{|c|c|c|c|}
\hline Variable & Men & Women & $\begin{array}{l}\text { Significance From } \\
\text { ANCOVA }\end{array}$ \\
\hline
\end{tabular}

Rest blood flow $\left(\mathrm{mL} / 100 \mathrm{~mL} \cdot \mathrm{min}^{-1}\right)$

$\begin{array}{llll}\text { Younger group } & 3.94 \pm 2.61 & 3.72 \pm 2.53 & \text { Age; } \mathrm{p}=0.331 \\ \text { Middle-aged group } & 2.68 \pm 2.74 & 3.24 \pm 2.83 & \text { Gender; } \mathrm{p}=0.465 \\ \text { Older group } & 2.98 \pm 2.58 & 3.99 \pm 2.59 & \text { Age } \times \text { gender; } \mathrm{p}=0.598\end{array}$

PORH blood flow $\left(\mathrm{mL} / 100 \mathrm{~mL} \cdot \mathrm{min}^{-1}\right)$

$\begin{array}{lrrl}\text { Younger group } & 10.35 \pm 6.06 & 11.21 \pm 5.87 & \text { Age; } \mathrm{p}=0.075 \\ \text { Middle-aged group } & 7.35 \pm 6.35 & 9.31 \pm 6.57 & \text { Gender; } \mathrm{p}=0.454 \\ \text { Older group } & 7.35 \pm 5.98 & 7.75 \pm 5.98 & \text { Age } \times \text { gender; } \mathrm{p}=0.836\end{array}$

PORH $\% \Delta$ from rest

$\begin{array}{llll}\text { Younger group } & 167 \pm 164 & 226 \pm 158 & \text { Age; } \mathrm{p}=0.269 \\ \text { Middle-aged group } & 150 \pm 172 & 212 \pm 177 & \text { Gender; } \mathrm{p}=0.379 \\ \text { Older group } & 147 \pm 161 & 128 \pm 161 & \text { Age } \times \text { gender; } \mathrm{p}=0.458\end{array}$

Maximal blood flow $\left(\mathrm{mL} / 100 \mathrm{~mL} \cdot \mathrm{min}^{-1}\right)$

$\begin{array}{llll}\text { Younger group } & 26.78 \pm 11.10 & 24.88 \pm 10.53 & \text { Age; } \mathrm{p}=0.302 \\ \text { Middle-aged group } & 19.98 \pm 11.48 & 23.98 \pm 11.88 & \text { Gender; } \mathrm{p}=0.915 \\ \text { Older group } & 24.23 \pm 10.70 & 21.28 \pm 10.76 & \text { Age } \times \text { gender; } \mathrm{p}=0.305\end{array}$

Maximal \% $\Delta$ from rest

$\begin{array}{llll}\text { Younger group } & 635 \pm 498 & 711 \pm 482 & \text { Age; } \mathrm{p}=0.934 \\ \text { Middle-aged group } & 597 \pm 522 & 799 \pm 540 & \text { Gender; } \mathrm{p}=0.561 \\ \text { Older group } & 696 \pm 492 & 623 \pm 491 & \text { Age } \times \text { gender; } \mathrm{p}=0.452\end{array}$

Values were adjusted for body weight, body mass index, and ankle/brachial index.

Sample sizes of the groups are as follows: younger men $(n=19)$, younger women $(n=15)$, middle-aged men $(n=21)$, middle-aged women $(n=23)$, older men $(n=17)$, older women $(n=23)$. ANCOVA $=$ analysis of covariance; $\mathrm{PORH}=$ postocclusive reactive hyperemia.

Table IV. Correlation coefficients between clinical and hemodynamic measurements.

\begin{tabular}{lccccc}
\hline & $\begin{array}{c}\text { Rest Calf } \\
\text { Blood Flow }\end{array}$ & $\begin{array}{c}\text { PORH } \\
\text { Blood Flow }\end{array}$ & $\begin{array}{c}\text { \% Increase } \\
\text { From Rest }\end{array}$ & $\begin{array}{c}\text { Max Blood } \\
\text { Flow }\end{array}$ & $\begin{array}{c}\text { \% Increase } \\
\text { From Rest }\end{array}$ \\
\hline Age & -0.038 & -0.151 & -0.114 & -0.164 & -0.099 \\
Weight & $0.198^{*}$ & -0.177 & $-0.300^{\dagger}$ & $-0.265^{\dagger}$ & $-0.265^{\dagger}$ \\
BMI & $0.274^{\dagger}$ & -0.093 & $-0.261^{\dagger}$ & $-0.276^{\dagger}$ & $-0.316^{\dagger}$ \\
\hline
\end{tabular}

*Significant correlation coefficient $(\mathrm{p}<0.05) .{ }^{\dagger}(\mathrm{p}<0.01) . \mathrm{BMI}=$ body mass index; Max = maximal; $\mathrm{PORH}=$ postocclusive reactive hyperemia. 
should be encouraged throughout young, middle, and old age.

\section{Summary and Conclusion}

In summary, the major findings of this investigation were the following: (1) younger, middleaged, and older women had a greater percentage change in calf blood flow from rest to PORH than men; (2) after adjustment for body weight, BMI, and $\mathrm{ABI}$, the gender differences in the percentage change in calf blood flow from rest to PORH were no longer evident; and (3) BMI was negatively and significantly related to the percentage changes in calf blood flow from rest to PORH and maximal hyperemia, and to the absolute value of calf blood flow obtained during maximal hyperemia. We conclude that in a healthy cohort free of cardiovascular disease, increased BMI accounted for poorer vascular reactivity in men compared to women regardless of age.

\section{REFERENCES}

1. Ishida S, Hamasaki S, Kamekou M, et al: Advancing age is associated with diminished vascular remodeling and impaired vasodilation in resistance coronary arteries. Coron Artery Dis 14:443-449, 2003.

2. Galasse SP, Selwyn AP, Ganz P: Atherosclerosis: Risk factors and the vascular endothelium. Am Heart J 131:379-384, 1996.

3. Mano TT, Mysuyama K, Yamamoto K, et al: Endothelial dysfunction in the early stage of atherosclerosis precedes appearance of intimal lesions assessable with intravascular ultrasound. Am Heart J 131:231238, 1996.

4. Johnson MT, Creager SJ, Scales KM, et al: Impaired endothelium-dependent vasodilation in patients with insulin-dependent diabetes mellitus. Circulation 88: 2510-2516, 1993.

5. Taddei S, Virdis A, Mattei P, et al: Hypertension causes premature aging of endothelial function in humans. Hypertension 29:736-743, 1997.

6. Creager MA, Cooke JP, Mendelsohn ME, et al: Impaired vasodilation of forearm resistance vessels in hypercholesterolemic humans. J Clin Ivest 86:228234, 1990.

7. Celermajer DS, Sorensen FE, Spegeelhalter DJ, et al: Aging is associated with endothelial dysfunction in healthy men years before the age-related decline in women. J Am Coll Cardiol 24:471-476, 1994.
8. Calermajer DS, Sorensen KE, Bull C, et al: Endothelium dependent dilation in the systemic arteries of asymptomatic subjects relates to coronary risk factors and their interaction. J Am Coll Cardiol 24:14681474, 1994.

9. Jensen-Urstad K, Johansson J: Gender differences in age-related changes in vascular function. J Int Med 250:29-36, 2001.

10. Schwertz DW, Penckofer S: Sex differences and the effect of sex hormones on hemostasis and vascular reactivity. Heart Lung 30:401-428, 2001.

11. DeSouza CA, Shapiro L, Clevenger CM, et al: Regular aerobic exercise prevents and restores age-related declines in endothelium-dependent vasodilation in healthy men. Circulation 102:1351-1357, 2000.

12. Moncada S, Radomski MW, Palmer RJM: Endothelium derived relaxing factor: Identification as nitric oxide and role in the control of vascular tone and platelet function. Biochem Pharmacol 37:2495-2501, 1988.

13. Goodwin AT, Amrani M, Marchbank AJ, et al: Coronary vasoconstriction to endothelin-1 increases with age before and after ischemia and reperfusion. Cardiovasc Res 41:554-562, 1999.

14. Gerhard M, Roddy M, Creager SJ, et al: Aging progressively impairs endothelium dependent vasodilation in forearm resistance vessels of humans. Hypertension 27:849-853, 1996.

15. Mayhan WG, Faraci FM, Baumbach GL, et al: Effects of aging on responses of cerebral arterioles. Am J Physiol 258:H1138-H1143, 1990.

16. Perticone F, Ceravolo R, Candigliota M, et al: Obesity and body fat distribution induce endothelial dysfunction by oxidative stress: Protective effect of vitamin C. Diabetes 50:159-165, 2001.

17. Gardner AW, Montgomery PS: Impaired balance and higher prevalence of falls in subjects with intermittent claudication. J Gerontol Med Sci 56A:M454M458, 2001.

18. Gardner AW, Skinner JS, Cantwell BW, et al: Progressive vs single-stage treadmill tests for evaluation of claudication. Med Sci Sports Exerc 23:402-408, 1991.

19. Gardner AW, Sieminski DJ, Killewich LA: The effect of cigarette smoking on free-living daily physical activity in older claudication patients. Angiology 48: 947-955, 1997.

20. Nakanishi N, Suzuki K, Tatara K: Clustered features of the metabolic syndrome and the risk for increased aortic pulse wave velocity in middle-aged Japanese men. Angiology 54:551-559, 2003.

21. Coviello JS, Nystrom KV: Obesity and heart failure. J Cardiovasc Nurs 18:360-366, 2003.

22. Thakur V, Richards R, Reisin E: Obesity, hypertension and the heart. Am J Med Sci 321:242-248, 2001.

23. Lima de Gusmao-Correia M, Haynes WG: Leptin, obesity and cardiovascular disease. Curr Opin Nephrol Hypertension 13:215-223, 2004. 